\title{
Wpływ rodzaju lutu mosiężnego na właściwości złączy lutowanych
}

\section{The influence of the brass solder type on the brazed joints properties}

\section{Streszczenie}

W pracy przedstawiono wyniki badań złączy lutowanych końcówek elastycznych przewodów hamulcowych. Do lutowania indukcyjnego użyto czterech lutów na osnowie miedzi oraz topnika w postaci pasty.

Przeprowadzono badania wizualne, metalograficzne i wytrzymałości złączy na ścinanie. Zaprezentowano zależność wytrzymałości złączy lutowanych od rodzaju użytego lutu. Opracowano instrukcję technologiczną lutowania.

\section{Wstęp}

Konsekwencją intensywnego rozwoju przemysłu motoryzacyjnego jest zwiększone zapotrzebowanie na hydraulikę siłową, w tym również na przewody hamulcowe z lutowanymi końcówkami. Przewody hamulcowe są narażone na działanie wysokiego ciśnienia, dlatego też dobra jakość, duża wytrzymałość, szczelność połączenia oraz dokładna kontrola jakości są warunkami ich produkcji.

Najważniejszym powodem, dla którego jakość przewodów hamulcowych jest istotna, jest jednak bezpieczeństwo użytkowników pojazdów.

W masowej produkcji przewodów hamulcowych do lutowania końcówek stosuje się lutowanie piecowe i najczęściej lut miedziany w postaci pasty. W produkcji jednostkowej i przy różnorodnym asortymencie końcówki przewodów hamulcowych lutowane są

Dr inż. Piotr Białucki, prof. dr hab. inż. Andrzej Ambroziak, dr inż. Wiesław Derlukiewicz, mgr inż. Michał Kowalski - Politechnika Wrocławska.

\section{Abstract}

This paper presents the results of soldered joints flexible brake hoses endings. The induction brazing with the use four copper-based solders and flux in paste form was applied.

Visual tests, metallographic investigation as well as shear strength tests of soldered joints were carried out. The relationship between strength of soldered joints and the type of solder was given. The Brazing Proceedings Specification BPS was developed.

płomieniowo lub indukcyjnie z użyciem lutów mosiężnych.

W pracy dokonano oceny jakości końcówek przewodów hamulcowych lutowanych indukcyjnie z użyciem czterech lutów mosiężnych: LM63, LM60C, LM60K i LM60S.

\section{Charakterystyka części lutowanej przewodu hamulcowego}

Przewody hamulcowe stanowią ważne elementy hydrauliczne układu hamulcowego w samochodzie. Można je podzielić na dwie podgrupy: przewody sztywne oraz elastyczne. Przewody sztywne to metalowe rurki, których zadaniem jest doprowadzenie płynu hamulcowego od pompy hamulcowej do przewodów elastycznych oraz elementów wykonawczych, np. zacisków. Przewody elastyczne są zbudowane z gumy wzmocnionej wewnątrz i na zewnątrz plecionką z tkaniny oraz dodatkowo oplotem metalowym. Łączą 
one elementy, które są ruchome względem siebie. Muszą też być odporne na oddziaływanie płynu hamulcowego. Każdy element przewodu hamulcowego musi się charakteryzować odpowiednią wytrzymałością w zakresie ciśnień roboczych całego układu [1].

Przedmiotem badań były końcówki elastycznych przewodów hamulcowych, których przykład pokazano na rysunku 1. Schemat złącza lutowanego końcówki przedstawiono na rysunku 2.

Elementy końcówki wykonano ze stali automatowej 11SMn30, której skład chemiczny podano w tablicy I.

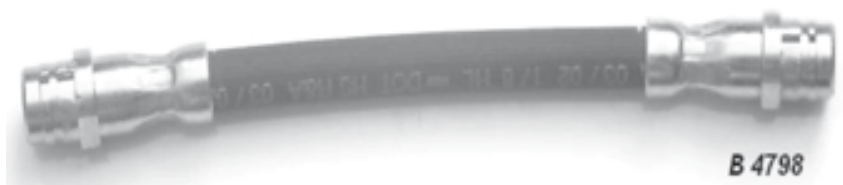

Rys. 1. Przykładowy przewód hamulcowy (Volkswagen, model Golf IV) [2]

Fig. 1. An example of brake hose (Volkswagen Golf IV) [2]

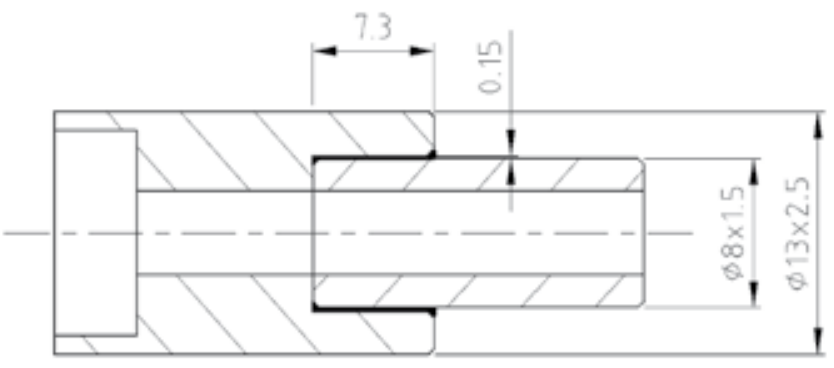

Rys. 2. Konstrukcja połączenia lutowanego końcówek przewodu hamulcowego

Fig. 2. Construction of brazed joints of brake's hose endings

Tablica I. Skład chemiczny stali $11 \mathrm{SMn} 30$ i jej wytrzymałość $[3,7]$

Table I. Chemical composition of steel $11 \mathrm{SMn} 30$ and its strength $[3,7]$

\begin{tabular}{|c|c|c|c|c|c|c|c|}
\hline \multirow{2}{*}{ Znak stali } & \multicolumn{5}{|c|}{ Średnie stężenie pierwiastków, \% wag., reszta Fe } & \multirow{2}{*}{$\begin{array}{c}\mathrm{R}_{\mathrm{m}} \\
\mathrm{MPa}\end{array}$} & \multirow{2}{*}{ Uwagi } \\
\hline & $\mathrm{C}$ & $\mathrm{Mn}$ & $\mathrm{Si}$ & $P$ & $S$ & & \\
\hline $11 S M n 30$ & 0,11 & 1,1 & 0,05 & 0,11 & 0,3 & $380-570$ & wg PN-EN 10204-3.1 \\
\hline $11 \mathrm{SMn} 30$ & 0,10 & 1,18 & 0,04 & 0,059 & 0,31 & 461 & wg atestu \\
\hline
\end{tabular}

Tablica II. Spoiwa mosiężne użyte w badaniach

Table II. Brass binders used in tests

\begin{tabular}{|c|c|c|c|c|c|c|}
\hline \multirow{2}{*}{$\begin{array}{c}\text { Oznaczenie wg } \\
\text { PN-70/M-69413 }\end{array}$} & \multirow{2}{*}{$\begin{array}{c}\text { Odpowiednik wg } \\
\text { PN-EN ISO 17672 }\end{array}$} & \multicolumn{4}{|c|}{ Skład chemiczny, \% wag. } & \multirow{2}{*}{$\begin{array}{c}\text { Orientacyjna } \\
\text { temperatura topnienia, }{ }^{\circ} \mathrm{C}\end{array}$} \\
\cline { 3 - 6 } & & $\mathrm{Cu}$ & $\mathrm{Zn}$ & $\mathrm{Sn}$ & $\mathrm{Si}$ & \\
\hline LM63 & - & $62-64$ & reszta & - & - & 905 \\
\hline LM60C & $\mathrm{Cu} 470$ & $59-61$ & reszta & $1,0-1,5$ & $\max 0,1$ & 900 \\
\hline LM60K & Cu 470a & $59-61$ & reszta & - & $0,2-0,4$ & 900 \\
\hline LM60S & - & $58-60,5$ & reszta & $0,15-0,4$ & $0,1-0,3$ & 900 \\
\hline
\end{tabular}

Do lutowania twardego końcówek hamulcowych (rys. 2), wykonanych ze stali 11SMn30, użyto czterech lutów mosiężnych przedstawionych w tablicy II.

W procesie lutowania indukcyjnego stosowano topnik z grupy FH20 (wg PN-EN 1045) w postaci pasty o oznaczeniu handlowym D54, który jest powszechnie używany przy lutowaniu lutami mosiężnymi. Temperaturowy zakres aktywności tego topnika wynosi $700 \div 1000^{\circ} \mathrm{C}$.

\section{Lutowanie końcówek przewodów hamulcowych}

Proces lutowania przeprowadzano przy użyciu nagrzewnicy indukcyjnej DB-1.01 o mocy $8,5 \mathrm{~kW}$, przedstawionej na rysunku 3. Czas trwania procesu nagrzewania wynosił ok. $4 \mathrm{~s}$. Temperaturę lutowania kontrolowano bezstykowo za pomocą pirometru optycznego. Warunki lutowania zawarto w instrukcji technologicznej lutowania BPS przedstawionej w tablicy III.

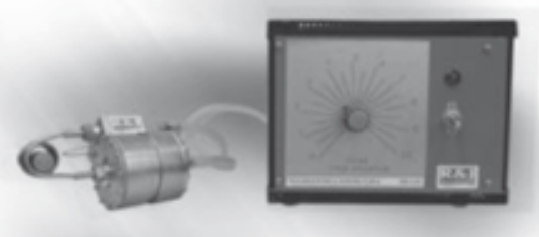

Rys. 3. Nagrzewnica indukcyjna DB-1.01

Fig 3. Induction Heater DB-1.01 
Na rurkę o średnicy $8 \mathrm{~mm}$ nakładano lut w postaci pierścionka $z$ drutu o średnicy $1,2 \mathrm{~mm}$, następnie na powierzchnię złącza nanoszono pędzelkiem topnik D54. Przebieg procesu pokazano na rysunku 4.

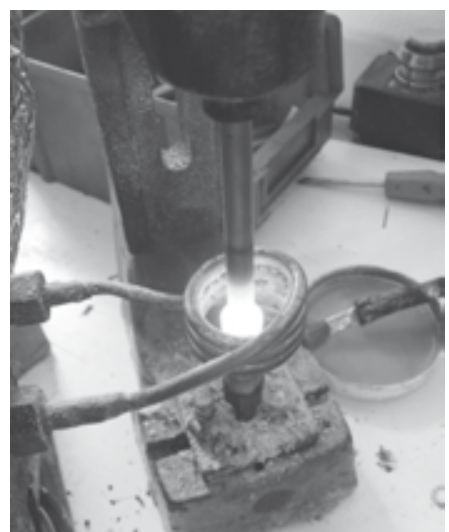

Rys. 4. Proces lutowania indukcyjnego końcówki przewodu hamulcowego

Fig. 4. The process of induction brazing of endings of brake hose

\section{Badania wizualne}

Badania wizualne złączy lutowanych wykonano zgodnie z norma PN-EN 12799. Ocenie podlegała geometria złącza i wygląd powierzchni lutowiny. Na rysunkach 5 i 6 przedstawiono złącza lutowane badanymi lutami.

Badane złącza dla wszystkich rodzajów lutu były wysokiej jakości. Miały estetyczny wygląd i poprawnie ukształtowaną lutowinę. Najwyższą ocenę uzyskały złącza wykonane lutem LM60K (rys. 5c). W przypadku pozostałych lutów występowały drobne pory powierzchniowe (2BALF) oraz miejscowe rozpłynięcie się lutowiny po powierzchni bocznej łączonych części (7QAAA).
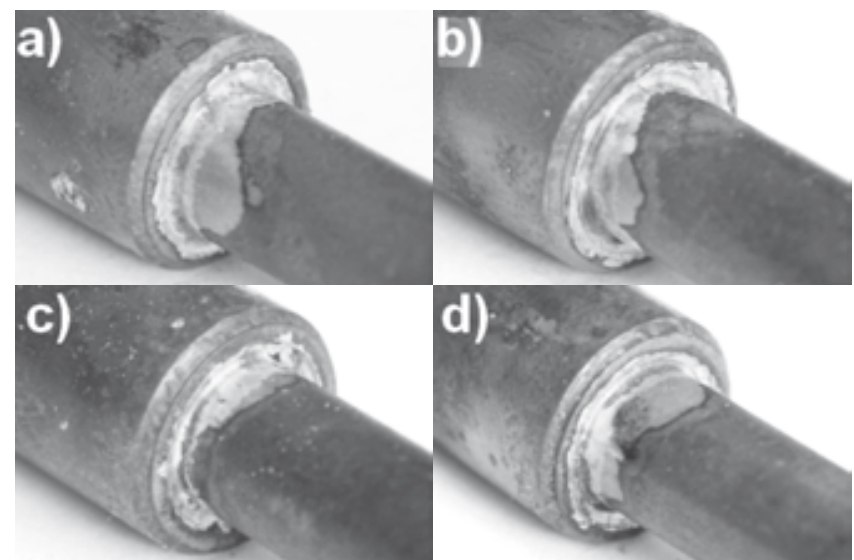

Rys. 5. Powierzchnia lutowiny końcówek przewodów hamulcowych wykonanych przy użyciu lutów: a) LM63, b) LM60C, c) LM60K, d) LM60S

Fig. 5. The surface appearance of solder joints of brake's hose endings made using four types of solders: a) LM63, b) LM60C, c) LM60K, d) LM60S

\section{Badania szczelności}

Szczelność połączenia końcówek badano na kompletnym przewodzie hamulcowym, który pokazano na rysunku 6 . Do badań przygotowano 8 przewodów z dwiema końcówkami z każdego lutu, których szczelność sprawdzano na stanowisku pokazanym na rysunku 7 . Badania prowadzono przy ciśnieniu $22 \mathrm{MPa}$ utrzymywanym przez $2 \div 3$ min. Ciśnienie próbne było trzykrotnie wyższe niż ciśnienie pracy przewodów wynoszące $7 \mathrm{MPa}$.

Wszystkie złącza wykazały pełną szczelność.

\section{Próby wytrzymałości na ścinanie}

Statycznej próbie na ścinanie poddano 12 próbek, po 3 próbki z każdego rodzaju lutu. Próbki do badań przygotowano obróbką toczeniem, zachowując szerokość zakładki nie większą niż $2 \mathrm{~mm}$, tak aby zniszczenie złącza nastąpiło w lutowinie. Szerokość szczeliny lutowniczej dla wszystkich próbek wynosiła $0,15 \mathrm{~mm}$. Przykłady próbek pokazano na rysunku 8 , a wyniki badań zamieszczono $w$ tablicy IV.

Z przeprowadzonych prób wynika, że największą wytrzymałość na ścinanie, wynoszącą $240 \mathrm{MPa}$, miały złącza wykonane lutem LM60K, a najmniejszą wytrzymałość wykazały złącza lutowane lutem LM 60C. Wytrzymałość złączy lutowanych pozostałymi lutami LM63 i LM60S była ok. 3\% niższa od złączy wykonanych lutem LM60K, co zilustrowano na rysunku 9.

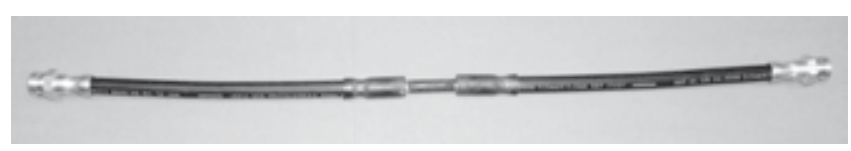

Rys. 6. Przewód hamulcowy przygotowany do badania szczelności końcówek lutowanych

Fig. 6. The appearance of the brake hose prepared for the leakage test of soldered endings

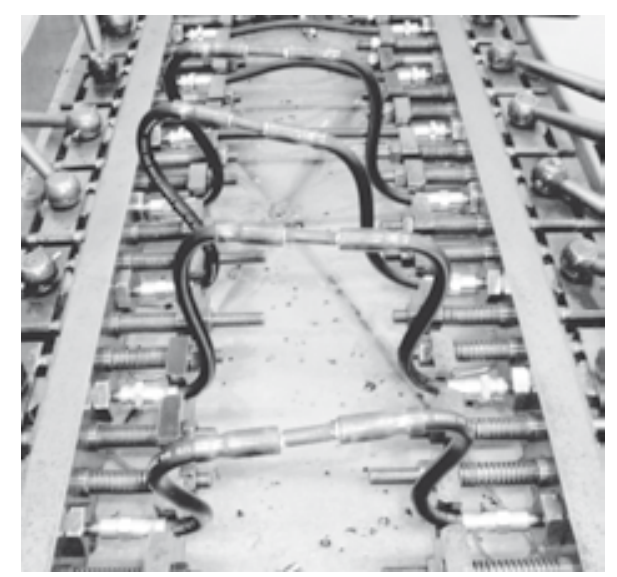

Rys. 7. Stanowisko do badania szczelności lutowanych końcówek przewodów hamulcowych

Fig. 7. Stand for the leakage test of soldered endings of brake lines 
Tablica III. Instrukcja technologiczna lutowania BPS

Table III. Brazing Proceedings Specification BPS

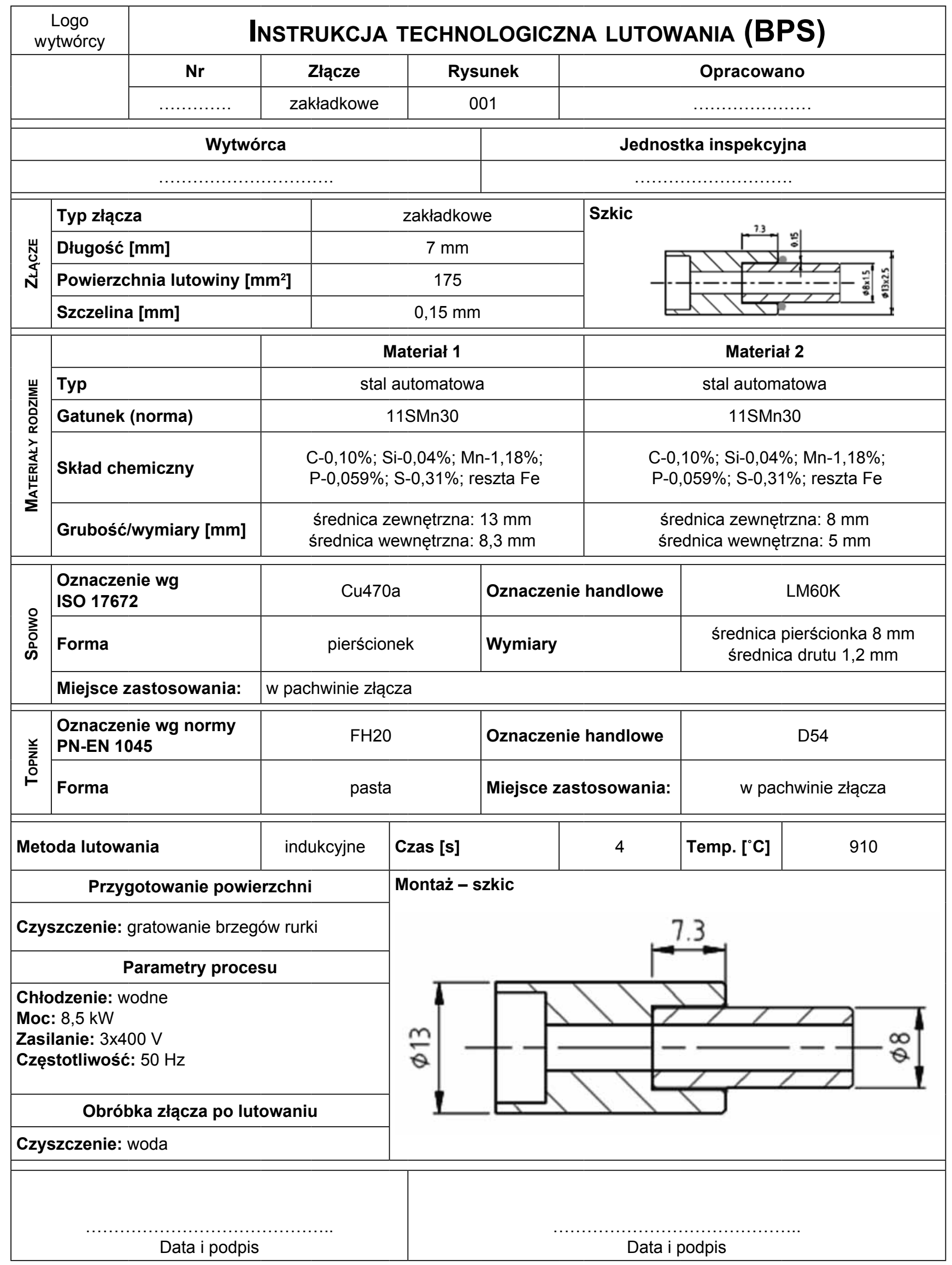


Tablica IV. Wyniki statycznej próby ścinania złączy lutowanych końcówek przewodów hamulcowych Table IV. Results of shear strength tests of brazed joints of brake hose endings

\begin{tabular}{|c|c|c|c|c|c|}
\hline Lut & Średnica próbki & $\begin{array}{c}\text { Szerokość zakładki } \\
\mathrm{mm}\end{array}$ & $\begin{array}{c}\text { Siła ścinająca } \\
\text { kN }\end{array}$ & $\begin{array}{c}\text { Wytrzymałość } \\
\mathrm{R}_{\mathrm{t}}, \mathrm{MPa} \\
\end{array}$ & $\begin{array}{c}\text { Średnia wytrzymałość } \\
\mathrm{R}_{\mathrm{t}}, \mathrm{MPa} \\
\end{array}$ \\
\hline \multirow{3}{*}{ LM63 } & \multirow{3}{*}{8,1} & 2,10 & 12,7 & 237,3 & \multirow{3}{*}{233} \\
\hline & & 2,05 & 11,8 & 226,3 & \\
\hline & & 1,95 & 11,8 & 237,9 & \\
\hline \multirow{3}{*}{ LM60C } & \multirow{3}{*}{8,1} & 1,90 & 10,9 & 225,5 & \multirow{3}{*}{218} \\
\hline & & 1,90 & 10,4 & 215,2 & \\
\hline & & 2,05 & 11,1 & 212,9 & \\
\hline \multirow{3}{*}{ LM60K } & \multirow{3}{*}{8,1} & 2,10 & 12,7 & 237,7 & \multirow{3}{*}{240} \\
\hline & & 2,00 & 12,2 & 239,8 & \\
\hline & & 1,85 & 11,4 & 242,2 & \\
\hline \multirow{3}{*}{ LM60S } & \multirow{3}{*}{8,1} & 1,90 & 11,3 & 234,4 & \multirow{2}{*}{233} \\
\hline & & 2,05 & 12,1 & 232,1 & \\
\hline & & 1,90 & 8,4 & 173,8 & - \\
\hline
\end{tabular}

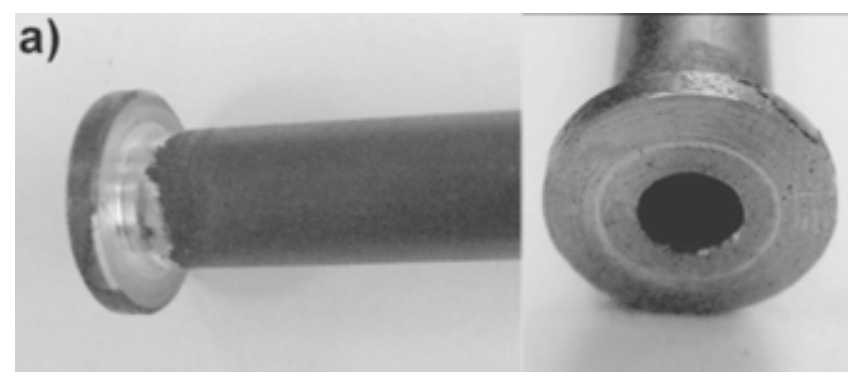

b)

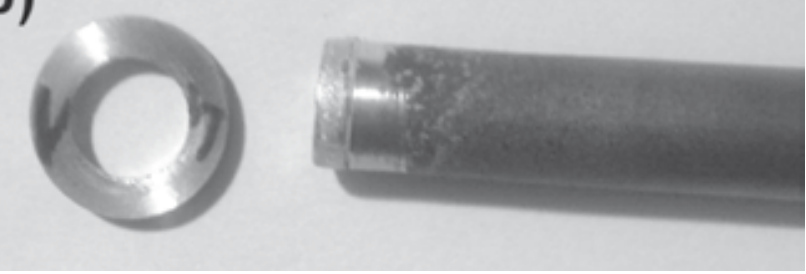

Rys. 8. Próbki do badań wytrzymałości na ścinanie: a) po toczeniu, b) po ścięciu

Fig. 8. Appearance of samples for the shear strength test: a) before testing, b) after testing

\section{Badania metalograficzne}

Do badań metalograficznych wytypowano cztery złącza wycięte z końcówek lutowanych każdym rodzajem lutu. Badania polegały na obserwacji makrostruktur złączy lutowanych na mikroskopie

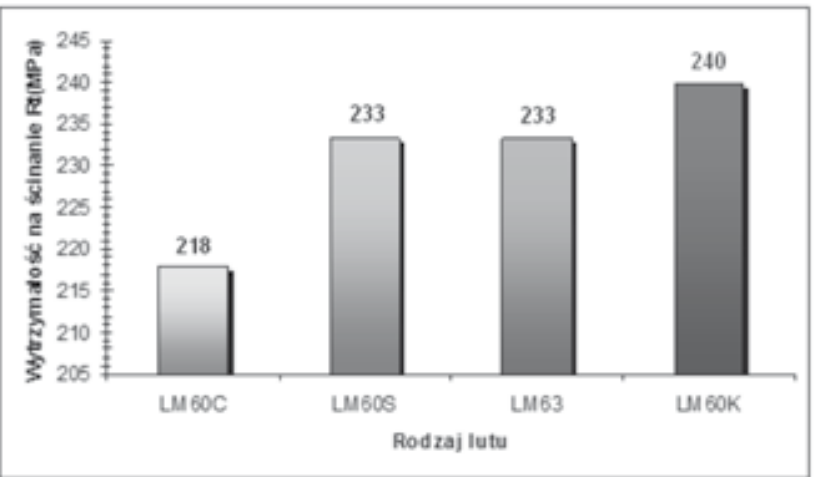

Rys. 9. Wytrzymałość na ścinanie złączy końcówek przewodów hamulcowych w zależności od rodzaju użytego lutu

Fig. 9. Shear strength joints brake hose endings depending on the type of solder

stereoskopowym Olympus SZX7 przy powiększeniu

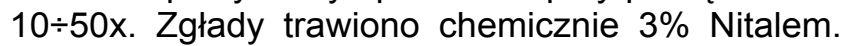
Przykładowe makrostruktury badanych złączy pokazano na rysunku 10.

W wyniku przeprowadzonych badań makroskopowych stwierdzono, że złącza wykonane lutem LM60K nie wykazują niezgodności wewnętrznych. Natomiast w pozostałych przypadkach stwierdzono występowanie małych pustek gazowych (2BAAA), dużych pustek gazowych (2LIAA) oraz niewypełnienie szczeliny lutowniczej (4JAAA). 

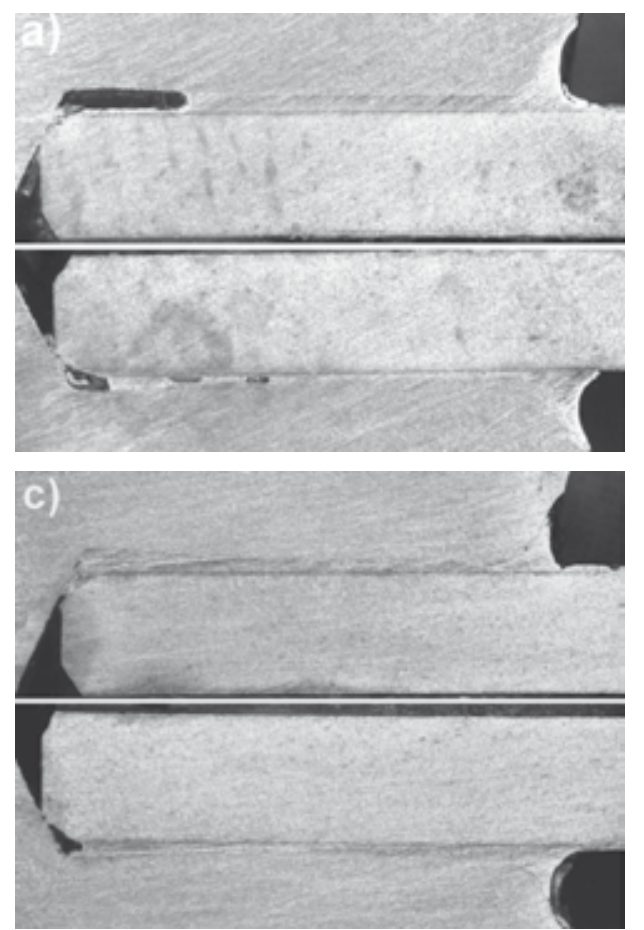
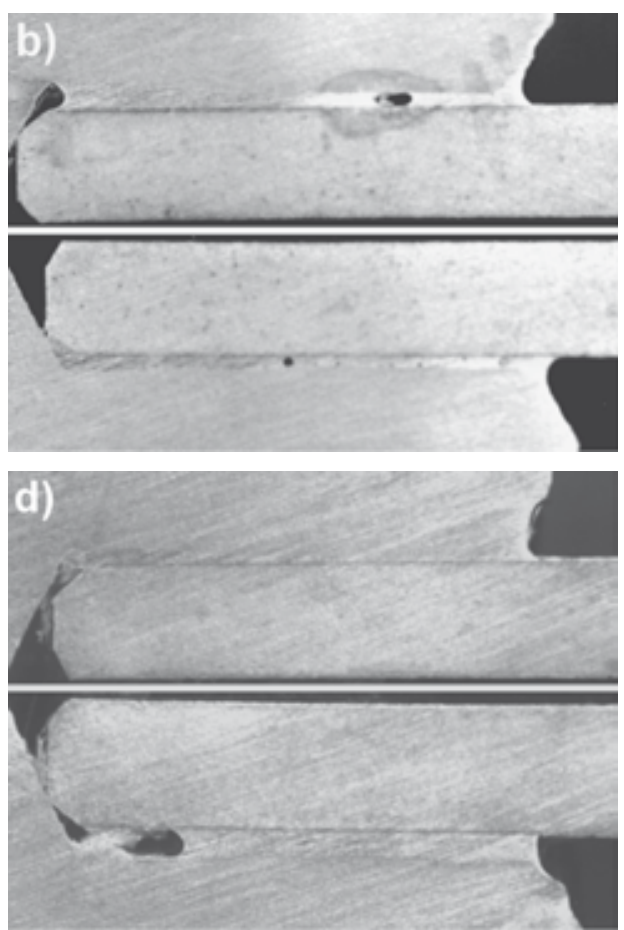

Rys. 10. Makrostruktury złączy lutowanych końcówek przewodów hamulcowych lutami: a) LM63, b) LM60C, c) LM60K, d) LM60S Fig. 10. Microstructure of brazed joints of brake hose endings with the use of brazers: a) LM63, b) LM60C, c) LM60K, d) LM60S

\section{Podsumowanie}

Na podstawie wykonanych badań można sformułować następujące wnioski:

- Metoda lutowania indukcyjnego jest dobrą metodą lutowania złączy końcówek przewodów hamulcowych. Zapewnia ona równomierne nagrzanie lutowanych elementów w bardzo krótkim czasie i pozwala uzyskać wymaganą jakość połączeń.

- Badania wizualne i metalograficzne wykazały, że najlepsze złącza uzyskuje się przy użyciu lutu LM60K.
- Wymaganą szczelność lutowanych końcówek przewodów hamulcowych uzyskano dla wszystkich badanych złączy.

- Największą wytrzymałość na ścinanie wynoszącą ok. $240 \mathrm{MPa}$ osiągnęły złącza wykonane przy użyciu lutu LM60K.

- Do lutowania indukcyjnego w końcówkach przewodów hamulcowych zaleca się stosować lut LM60K w postaci pierścionka $z$ drutu o średnicy $1,2 \mathrm{~mm}$ oraz topnik D54 w postaci pasty.

\section{Literatura}

[1] www.wikipedia.pl

[2] www.bogusz.com.pl

[3] Dobrzański L.A.: Metalowe materiały inżynierskie, WNT, Gliwice - Warszawa 2004.

[4] PN-EN ISO 17672:2010, Lutowanie twarde - Spoiwa.

[5] PN-EN 1045:2001, Lutowanie twarde - Topniki do lutowania twardego - Klasyfikacja i techniczne warunki dostawy.
[6] PN-EN ISO 18279:2008, Lutowanie twarde - Niezgodności w złączach lutowanych na twardo.

[7] Kowalski M.: Wpływ rodzaju lutu mosiężnego na właściwości złączy lutowanych występujących w końcówkach przewodów hamulcowych. Praca dyplomowa, Wydział Mechaniczny PWr, promotor dr inż. W. Derlukiewicz. 